\title{
Benign Thyroid Gland Neoplasm
}

National Cancer Institute

\section{Source}

National Cancer Institute. Benign Thyroid Gland Neoplasm. NCI Thesaurus. Code C3628.

A benign neoplasm arising from the thyroid gland. 